\title{
An Overview of PET Radiochemistry, Part 2: Radiometals
}

\author{
Marie Brandt ${ }^{1,2}$, Jens Cardinale ${ }^{1,2}$, Margaret L. Aulsebrook ${ }^{3}$, Gilles Gasser ${ }^{3}$, and Thomas L. Mindt ${ }^{1,2}$ \\ ${ }^{1}$ Ludwig Boltzmann Institute Applied Diagnostics, General Hospital of Vienna, Vienna, Austria; ${ }^{2}$ Department of Biomedical Imaging \\ and Image Guided Therapy, Division of Nuclear Medicine, Medical University of Vienna, Vienna, Austria; and ${ }^{3}$ Chimie ParisTech, \\ PSL University, Laboratory for Inorganic Chemical Biology, Paris, France
}

\begin{abstract}
Learning Objectives: On successful completion of this activity, participants should be able to (1) classify the most important PET radiometals currently applied in clinical routine and research; (2) know the advantages and disadvantages of the discussed radiometals and choose an appropriate radiometal for a given application; and (3) have a general overview of recent trends in the research field of PET radiometals.
\end{abstract}

Financial Disclosure: This work was financially supported by the Swiss National Science Foundation (grant SNSF 205321 157216 to Gilles Gasser and Thomas Mindt) and has received support under the program Investissements d' Avenir launched by the French Government and implemented by the ANR with the reference ANR10-IDEX-0001-02 PSL (Gilles Gasser). The authors of this article have indicated no other relevant relationships that could be perceived as a real or apparent conflict of interest.

CME Credit: SNMMI is accredited by the Accreditation Council for Continuing Medical Education (ACCME) to sponsor continuing education for physicians. SNMMI designates each JNM continuing education article for a maximum of 2.0 AMA PRA Category 1 Credits. Physicians should claim only credit commensurate with the extent of their participation in the activity. For CE credit, SAM, and other credit types, participants can access this activity through the SNMMI website (http://www.snmmilearningcenter.org) through October 2018.

This continuing educational review provides an overview on radiometals used for PET. General aspects of radiometal-based radiotracers are covered, and the most frequently applied metallic PET radionuclides, ${ }^{68} \mathrm{Ga},{ }^{89} \mathrm{Zr}$, and ${ }^{64} \mathrm{Cu}$, are highlighted with a discussion of their strengths and limitations.

Key Words: ${ }^{64} \mathrm{Cu}$; ${ }^{68} \mathrm{Ga}$; ${ }^{89} \mathrm{Zr}$; metallic PET radionuclides; theranostics

J Nucl Med 2018; 59:1500-1506

DOI: 10.2967/jnumed.117.190801

$\mathbf{T}$ he potential of radiometals in nuclear imaging goes well beyond the established ${ }^{99 \mathrm{~m}} \mathrm{Tc}$-radiopharmaceuticals used for SPECT. Concerning diagnostic imaging agents, the use of positron-emitting radiometals for PET is a rapidly growing field. For example, ${ }^{68} \mathrm{Ga}$ has become the clinical standard for the radiolabeling of somatostatin analogs (e.g., DOTATOC/TATE) and prostate-specific membrane antigen (PSMA) ligands (e.g., HBEDcc-PSMA) for the detection of neuroendocrine and prostate tumors, respectively.

In most targeted radiometal-based radiopharmaceuticals, the metal is bound to a pharmacophore by a bifunctional chelating agent (BFCA), which forms a stable covalent linkage between the label and the targeting ligand (vector) and ensures the stable complexation of the metal in vivo (Fig. 1). In many instances, the chelator and the vector are connected via a spacer moiety to separate the individual components of the conjugate to avoid potential interference. Chelators contain several functional groups for coordination to the radiometal of choice. This structural feature results not only in high kinetic and thermodynamic stability of

Received Jan. 30, 2018; revision accepted May 3, 2018.

For correspondence or reprints contact: Thomas L. Mindt, Ludwig Boltzmann Institute of Applied Diagnostics, General Hospital Vienna (AKH), c/o Sekretariat Nuklearmedizin, Währinger Gürtel 18-20, 1090 Wien, Austria. E-mail: thomas.mindt@lbiad.lbg.ac.at

Published online May 10, 2018.

COPYRIGHT (C) 2018 by the Society of Nuclear Medicine and Molecular Imaging. the complex but also usually in its fast and quantitative formation (chelate effect). Radiometal complexation with chelator-modified vectors offers convenient access to radiopharmaceuticals, for example, by enabling kit formulations. The choice of a chelator depends on the radiometal, which in turn is determined by the intended application. There are chelators that can be used in combination with different radiometals (e.g., DOTA for radiolabeling with ${ }^{68} \mathrm{Ga},{ }^{111} \mathrm{In}$, or ${ }^{177} \mathrm{Lu}$ ); however, optimized chelating systems tailor-made for individual radiometals are often available.

This review gives a short overview of the most frequently used radiometals for PET, their physical properties, suitable chelators, and examples of applications. Because ${ }^{68} \mathrm{Ga},{ }^{89} \mathrm{Zr}$, and ${ }^{64} \mathrm{Cu}$ are the most commonly applied radiometals in the clinic, they are discussed in more detail. Because of limitation of space, the examples included in this review are not exhaustive but selected for illustrative purposes.

Table 1 provides an overview on the physical properties and production routes of selected examples of PET radiometals, several of which are available in the high purity required for medical applications.

For imaging applications, the physical half-life of a radionuclide should match its intended application, or more specifically, the biologic half-life of the vector it is conjugated to. Short-lived radiometals are ideal in combination with vectors that exhibit fast pharmacokinetics (e.g., small molecules and peptides), whereas longer-lived radiometals are best suited for the imaging of slow biologic processes, such as the biodistribution of antibodies (immuno-PET) (1). A low $\beta^{+}$energy is another important aspect, since the positron's energy, and consequently its tissue penetration range till annihilation with an electron, determines the resolution of the PET image. A high positron intensity is also desired, as well as preferably no other radiation emitted from the same nucleus. Concomitant high-energy $\gamma$ or particle $\left(\alpha, \beta^{-}\right)$radiation can affect the quality of PET images or cause an unnecessary radiation dose to the patient.

The increasing number of publications concerning applications of PET radiometals over the past $20 \mathrm{y}$ (Fig. 2) could be ascribed to several factors. First, the introduction of commercial ${ }^{68} \mathrm{Ge} /{ }^{68} \mathrm{Ga}$ 


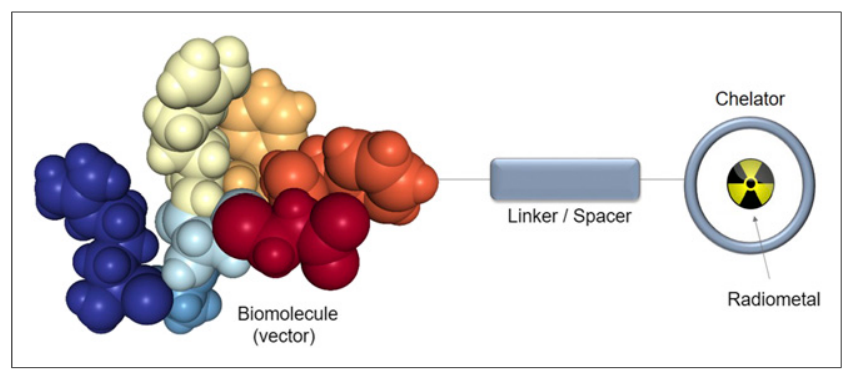

FIGURE 1. Schematic sketch of targeted metal-based radiopharmaceutical.

generators and the establishment of ${ }^{68} \mathrm{Ga}$-DOTATOC/TATE (2) in the early 21 st century have inspired researchers to investigate more intensively the use ${ }^{68} \mathrm{Ga}$-labeled compounds. Second, the worldwide ${ }^{99} \mathrm{Mo}$ (and therefore ${ }^{99 \mathrm{~m}} \mathrm{Tc}$ ) shortage around 2010 (3) stimulated an increased interest not only in alternative SPECT radionuclides but also in PET radiometals. Third, the increased availability of ${ }^{89} \mathrm{Zr}$ and ${ }^{64} \mathrm{Cu}$ through commercial sources, together with the growing general interest in antibodies and immunoconjugates, has promoted the employment of these radiometals.

A comparison of the number of clinical trials reflects the high importance and popularity of ${ }^{68} \mathrm{Ga}$ (Fig. 2). Interestingly, there are currently more clinical trials with ${ }^{89} \mathrm{Zr}$ than with ${ }^{64} \mathrm{Cu}$, although more reports of the latter can be found in the literature. The fact that clinical trials with ${ }^{89} \mathrm{Zr}$ involve almost exclusively applications of radiolabeled antibodies is an indicator that ${ }^{89} \mathrm{Zr}$ has become the radiometal of choice for immuno-PET.

An important advantage of using radiometals in radiopharmaceutical development is the possibility of exchanging a diagnostic with a therapeutic radiometal and, thus, converting an imaging probe into a therapeutic agent. This strategy has been termed theranostics (or sometimes theragnostics) (4). However, different definitions of theranostics can be found in the literature.

One definition is the use of radionuclides emitting both diagnostic and therapeutic radiations (e.g., ${ }^{177} \mathrm{Lu}\left[\beta^{-}, \gamma\right](5)$ or ${ }^{64} \mathrm{Cu}$ $\left.\left[\beta^{-}, \beta^{+}\right]\right)(6)$. This enables the use of the same radiopharmaceutical for both imaging and therapy by adjusting the applied dose. In addition, this allows for imaging during therapy.
Another definition is a matched-pair constellation, which is best described by the use of the same pharmacophore in combination with different diagnostic and therapeutic radionuclides. This includes, for example, ${ }^{99 \mathrm{~m}} \mathrm{Tc} /{ }^{186 / 188} \mathrm{Re}$ (4) or the currently most frequently used combination, ${ }^{68} \mathrm{Ga} /{ }^{177} \mathrm{Lu}$. Other matched pairs of radiometals have been reported, but it is important to recall that both the reporter probe (imaging) and the therapeutic agent must exhibit very similar (ideally identical) pharmacokinetics, which is not necessarily always the case (7).

A third definition is a isotopic pair (or true pair), which refers to the situation in which different isotopes of the same element are used for diagnostic and therapeutic applications (e.g., ${ }^{86} \mathrm{Y}\left(\beta^{+}\right)$ and $\left.{ }^{90} \mathrm{Y}\left(\beta^{-}\right)\right)$. This approach gives radiopharmaceuticals of equal biologic properties because they are chemically identical (8). In some cases, this can be an advantage, such as in dosimetry studies.

Regardless of the definition (and other aspects) (9), theranostic approaches provide exciting prospects for future innovation in radiopharmaceutical and nuclear medicinal research.

\section{${ }^{68} \mathrm{Ga}$ IN NUCLEAR MEDICINE}

${ }^{68} \mathrm{Ga}$ was already available from a ${ }^{68} \mathrm{Ge} /{ }^{68} \mathrm{Ga}$ generator long before ${ }^{18} \mathrm{~F}$ became broadly accessible (10). In fact, ${ }^{68} \mathrm{Ga}$ was the radionuclide that Anger and Gottschalk used for experiments with one of the first positron camera systems in the early 1960s (11). However, it took until the early 21 st century before ${ }^{68} \mathrm{Ga}$ became popular and widely used in nuclear medicine. Currently, it is one of the most prominent radiometals used for PET (2). The success of ${ }^{68} \mathrm{Ga}$ for PET applications has been driven by 2 factors: the availability of the radionuclide by generators and the concurrent development of excellent radiotracers as the driving force for its clinical use (9).

${ }^{68} \mathrm{Ga}$ became broadly accessible with the introduction of the Obninsk generator at the beginning of 21 st century (10). Roughly at the same time, the first clinical results with the currently established radiotracer ${ }^{68} \mathrm{Ga}$-DOTATOC/TATE were published $(12,13)$. Together, these resulted in a significant growth in the field of ${ }^{68} \mathrm{Ga}$ chemistry as reflected by the increasing number of publications (Fig. 2). Today, several ${ }^{68} \mathrm{Ga}$-labeled radiopharmaceuticals specific for different clinically relevant targets have been published

TABLE 1

Selected PET Radiometals, Their Physical Properties, and Prominent Production Modes

\begin{tabular}{|c|c|c|c|c|c|c|c|}
\hline Nuclide & Half-life & $\begin{array}{c}\mathrm{E}_{\text {乃max }} \\
(\mathrm{keV})\end{array}$ & $\begin{array}{l}\mathrm{I}_{\beta}^{+} \\
(\%)\end{array}$ & $\begin{array}{c}\text { Prominent } \\
\text { y-lines (keV) }\end{array}$ & $\begin{array}{l}\text { Daughter } \\
\text { nuclide }\end{array}$ & $\begin{array}{l}\text { Production } \\
\text { mode }\end{array}$ & Nuclear reaction \\
\hline \multirow[t]{2}{*}{${ }^{44} \mathrm{Sc}$} & $3.9 \mathrm{~h}$ & 1,474 & 94,3 & 1,157 & ${ }^{44} \mathrm{Ca}$ & Cyclotron & ${ }^{44} \mathrm{Ca}(p, n){ }^{44} \mathrm{Sc}^{-}$ \\
\hline & & & & & & Generator & ${ }^{45} \mathrm{Sc}(\mathrm{p}, 2 \mathrm{n}){ }^{44} \mathrm{Ti} \rightarrow{ }^{44} \mathrm{Sc}$ \\
\hline $52 \mathrm{gMn}$ & $5.5 \mathrm{~d}$ & 576 & 30 & 1,434 & ${ }^{52} \mathrm{Cr}$ & Cyclotron & ${ }^{52} \mathrm{Cr}(\mathrm{p}, \mathrm{n})^{52} \mathrm{Mn}$ \\
\hline${ }^{64} \mathrm{Cu}$ & $12.7 \mathrm{~h}$ & 653 & 17.8 & 1,346 & ${ }^{64} \mathrm{Ni}^{\star} /{ }^{64} \mathrm{Zn}{ }^{\dagger}$ & Cyclotron & ${ }^{64} \mathrm{Ni}(\mathrm{p}, \mathrm{n}){ }^{64} \mathrm{Cu}$ \\
\hline${ }^{68} \mathrm{Ga}$ & $67.6 \mathrm{~min}$ & 1,900 & 90 & 1,077 & ${ }^{68} \mathrm{Zn}$ & Generator & ${ }^{68} \mathrm{Ge} \rightarrow{ }^{68} \mathrm{Ga}+\beta^{-}$ \\
\hline${ }^{82} \mathrm{Rb}$ & $1.3 \mathrm{~min}$ & 3,350 & 96 & 776 & ${ }^{82} \mathrm{Kr}$ & Generator & ${ }^{82} \mathrm{Sr} \rightarrow{ }^{82} \mathrm{Rb}+\beta^{-}$ \\
\hline${ }^{86} Y$ & $14.7 \mathrm{~h}$ & 1,248 & 33 & 1,077 & ${ }^{86} \mathrm{Sr}$ & Cyclotron & ${ }^{86} \mathrm{Sr}(\mathrm{p}, \mathrm{n}){ }^{86} \mathrm{Y}$ \\
\hline${ }^{89} \mathrm{Zr}$ & $3.3 \mathrm{~d}$ & 897 & 22.3 & 909 & ${ }^{89} \mathrm{Y}$ & Cyclotron & ${ }^{89} \mathrm{Y}(\mathrm{p}, \mathrm{n})^{89} \mathrm{Zr}$ \\
\hline \multicolumn{8}{|c|}{$\begin{array}{l}{ }^{\star} \text { Daughter nuclide from positron decay. } \\
{ }^{\dagger} \text { Daughter nuclide from } \beta^{-} \text {decay. }\end{array}$} \\
\hline
\end{tabular}




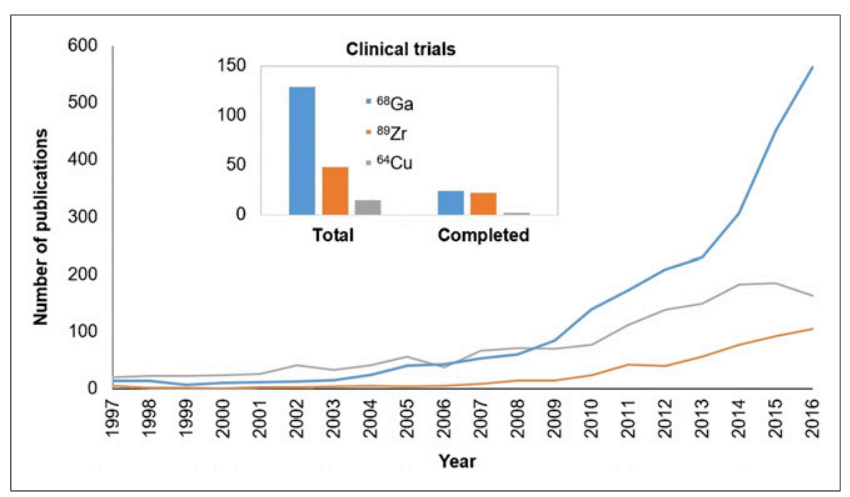

FIGURE 2. Number of publications with ${ }^{68} \mathrm{Ga},{ }^{89} \mathrm{Zr}$, and ${ }^{64} \mathrm{Cu}$ and number of clinical trials between 1997 and 2016. Databases used for determination of number of publications and clinical trials are Web of Science and clinicaltrials.gov, respectively. During preparation of this article, similar analysis was independently published (4).

or are available. Examples include ${ }^{68} \mathrm{Ga}$ radiotracers for the imaging of receptors such as various integrins, gastrin-releasing peptide receptor, glucagonlike peptide 1 receptor, vascular endothelial growth factor, chemokine receptor type 4, and PSMA $(2,14)$. Among these examples, the PSMA-targeting ligands (e.g., $\left.{ }^{68} \mathrm{Ga}-\mathrm{HBED}-\mathrm{cc}-\mathrm{PSMA}\right)$ had probably the highest impact in the field of ${ }^{68} \mathrm{Ga}$ PET in recent years. The main sources of ${ }^{68} \mathrm{Ga}$ are ${ }^{68} \mathrm{Ge} /{ }^{68} \mathrm{Ga}$ generators, in which ${ }^{68} \mathrm{Ga}$ is generated by the continuous decay of its long-lived mother nuclide ${ }^{68} \mathrm{Ge}$ (half-life, $270.9 \mathrm{~d}$ ). The cyclotron production of ${ }^{68} \mathrm{Ga}$ via the ${ }^{68} \mathrm{Zn}(\mathrm{p}, \mathrm{n}){ }^{68} \mathrm{Ga}$ reaction has recently gained interest because higher activities can be obtained (15). On the other hand, generators have some compelling features. The generator can be used for approximately $1 \mathrm{y}$, albeit the obtainable activity (and thus, the number of patient doses) is reduced to less than half the initial value. The regeneration of the generator after an elution takes approximately 3 half-lives of ${ }^{68} \mathrm{Ga}$, so that multiple productions of ${ }^{68} \mathrm{Ga}$-radiopharmaceuticals per day are possible. Currently, the maximum capacity of commercial generators is up to $1.8 \mathrm{GBq}$ of ${ }^{68} \mathrm{Ga}$ per elution, which translates to a maximum of about 3 preparations of 3 patient doses a day. In comparison to cyclotron-produced ${ }^{18} \mathrm{~F}$, this is a limitation. As discussed in a recent review (9), the consequence of this limitation (and several other factors) led the authors to conclude that ${ }^{68} \mathrm{Ga}$-based radiopharmaceuticals are more economic than ${ }^{18} \mathrm{~F}$-radiotracers only in certain cases. Still, the operation of ${ }^{68} \mathrm{Ga}$ generators is an interesting option for larger hospitals with a cyclotron facility because it allows for the parallel production of less frequently applied PET radiopharmaceuticals. On the other hand, ${ }^{68} \mathrm{Ga}$ offers an excellent opportunity for small facilities for the cyclotron-independent daily production of a few patient doses of different PET radiotracers.

From a chemist's point of view, ${ }^{68} \mathrm{Ga}^{3+}$ is a typical (radio)metal that prefers nitrogen and oxygen ligands for the formation of complexes. Thus, fast and quantitative ${ }^{68} \mathrm{Ga}$ radiolabeling of biomolecules can be achieved by the use of well-known chelators such as DOTA (1), NOTA (2), and HBED-cc (3) (Fig. 3). Besides these examples, there are a large number of alternative chelators available (16). More recent examples such as TRAP (4), DATA (5), and THP (6) (Fig. 3) enable efficient radiolabeling at room temperature, more acidic $\mathrm{pH}$, or lower concentrations of substrate. These attributes could facilitate ${ }^{68} \mathrm{Ga}$-kit preparations in the future.

Finally, the importance of the positron energy of a radionuclide for the quality of PET images is illustrated by the example of ${ }^{18} \mathrm{~F}$ and ${ }^{68} \mathrm{Ga}$. The maximum positron energy of ${ }^{68} \mathrm{Ga}$ is relatively high $(1.9 \mathrm{MeV})$ when compared with that of ${ }^{18} \mathrm{~F}(0.634 \mathrm{MeV})$, which is regarded as the positron emitter with the most favorable decay characteristics (17). The higher positron energy of ${ }^{68} \mathrm{Ga}$ results in a stronger partial-volume effect, which significantly reduces the accuracy of quantification based on SUVs, especially for small lesions. However, the difference in apparent image quality is less pronounced, which may be the reason for the common opinion that the difference observed for the 2 PET radionuclides is only marginal with clinical PET scanners.

\section{${ }^{89} \mathrm{Zr}$ AND ITS USE FOR IMMUNO-PET}

The drive behind the recent surge into ${ }^{89} \mathrm{Zr}$ PET is due to the suitable physical properties of the radiometal for antibody-based PET imaging (immuno-PET). The physical half-life of ${ }^{89} \mathrm{Zr}$ (Table 1) matches well the biologic window of most antibody formats and thus allows for optimal biodistribution to study the pharmacokinetics of antibodies and antibody conjugates.

The potential application of ${ }^{89} \mathrm{Zr}$-labeled antibodies in PET imaging was first demonstrated in 1997 (18). In this seminal paper, the authors reported a study with ${ }^{89} \mathrm{Zr}$ labeled anti-EpCam antibody 323/A3 for successful visualization of human xenografts in mice. A decade later, the first clinical application of ${ }^{89} \mathrm{Zr}$-immunoPET was reported (19). This study showcased the successful performance of ${ }^{89} \mathrm{Zr}$-labeled antibody U36 in patients with squamous cell carcinoma. Targeted tumor imaging using ${ }^{89} \mathrm{Zr}$ immunoPET has since grown impressively.

To date, the only chelator used in the clinic for ${ }^{89} \mathrm{Zr}$ radiolabeling is the hexadentate siderophore desferrioxamine (DFO; Fig. 4), which coordinates ${ }^{89} \mathrm{Zr}^{4+}$ through 3

FIGURE 3. Examples of chelators used for ${ }^{68} \mathrm{Ga}$-radiolabeling of molecules. 


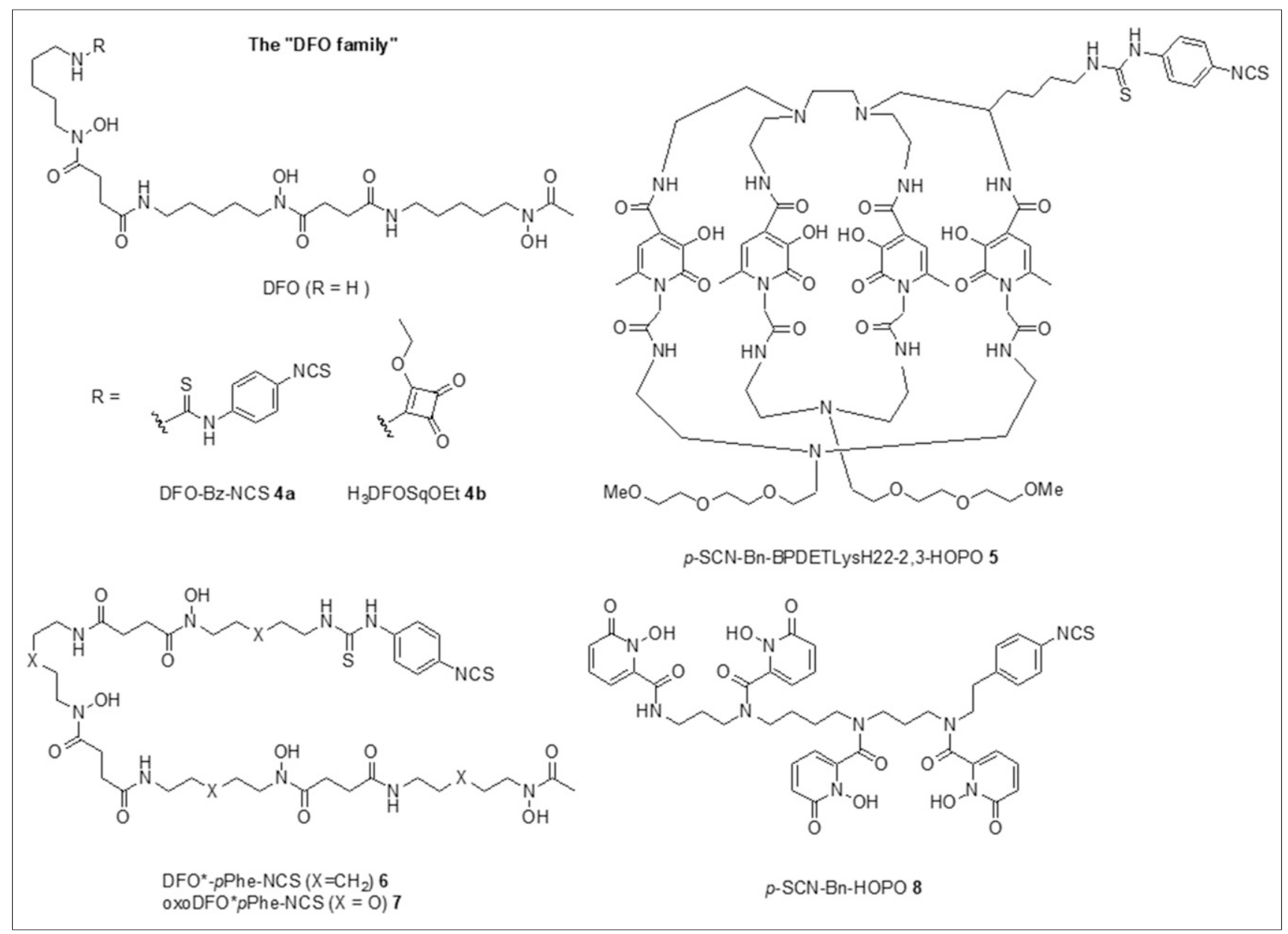

FIGURE 4. Examples of BFCAs for ${ }^{89} \mathrm{Zr}$ radiolabeling for which preclinical in vivo data are available.

hydroxamate groups (Fig. 4). Several recent reviews covering the history of ${ }^{89} \mathrm{Zr}$-DFO-labeled antibodies for applications in immunoPET imaging highlight the increasing interest in this topic $(20,21)$. However, preclinical reexamination of the DFO chelator suggested the instability of the ${ }^{89} \mathrm{Zr}-\mathrm{DFO}$ complex in vivo (20). Biodistribution studies of ${ }^{89} \mathrm{Zr}$-labeled antibodies in mice at late time points after injection of ${ }^{89} \mathrm{Zr}$-labeled antibodies showed unspecific uptake of the osteophilic radiometal in bones, which indicated in vivo decomplexation (22). Release of the radiometal from the ${ }^{89} \mathrm{Zr}$ DFO chelate and its subsequent sequestration in radiation-sensitive bones not only affects signal-to-background ratios but also raises concerns on the use of the chelator for clinical applications.

Over the last few years, several alternative BFCAs have been evaluated for the radiolabeling of antibodies with ${ }^{89} \mathrm{Zr}$; all reports have the common objective of increasing the stability of ${ }^{89} \mathrm{Zr}$ complexes. This new generation of BFCAs has an impressive array of different structural features with a focus on the development of ligands with 8 coordinative atoms for saturation of the octadentate coordination sphere of ${ }^{89} \mathrm{Zr}$ (Fig. 4). Because of the success of DFO, BFCAs incorporating the hydroxamate binding group are a popular design choice. This concept led to the development of a DFO analog termed DFO* (23). DFO* is an extension of the DFO scaffold with an additional hydroxamate group resulting in an octadentate chelator. In a later report, it was demonstrated that the BFCA DFO*-pPhe-NCS 6 (Fig. 4, $\mathrm{X}=\mathrm{CH}_{2}$ )
(24) could be conjugated to trastuzumab and radiolabeled with the same efficiency as commercial DFO- $p$ Bz-NCS 4a. The in vitro and in vivo characteristics of ${ }^{89} \mathrm{Zr}$-DFO*-trastuzumab were superior to those of ${ }^{89} \mathrm{Zr}$-Zr-DFO-modified trastuzumab. In xenografted mice, comparable tumor uptake was observed for the bioconjugates up to $144 \mathrm{~h}$ after injection. Importantly, significantly less uptake in bone, skin, liver, spleen, and ileum was observed for ${ }^{89} \mathrm{Zr}$-DFO*trastuzumab, thus demonstrating its superior performance in vivo. Current research directed toward further improvement of the DFO* system focuses on increasing its water solubility to facilitate bioconjugation chemistry (e.g., oxoDFO* 7, Fig. 4, X = O) (25).

The DFO scaffold has also been extended by incorporating a squaramide ester $\mathbf{4 b}$ (26). ${ }^{89} \mathrm{Zr}$-4b-trastuzumab gave high-quality PET images of HER2-positive tumors in a mouse model with a higher tumor-to-bone ratio than ${ }^{89} \mathrm{Zr}$-DFO-trastuzumab; however, an unexpectedly high uptake of radioactivity in the spleen was also observed. Reports of ${ }^{89} \mathrm{Zr}$-chelators consisting of multiple HOPO units indicated a higher stability than for the hydroxamate-based system of DFO (27). Consequently, the BFCA HOPO- $p$ Bn-NCS 8 was developed, conjugated to trastuzumab, and evaluated in ${ }^{89} \mathrm{Zr}$-labeled form (28). In comparison to ${ }^{89} \mathrm{Zr}$ DFO-trastuzumab, ${ }^{89} \mathrm{Zr}$-HOPO-trastuzumab showed less uptake of radioactivity in the bones, but accumulation in tumors was also reduced. The HOPO group has also been investigated in a macrobicyclic form of the BFCA $p$-SCN-Bn-BPDETLysH22-2,3-HOPO 
5 (29). Evaluation of ${ }^{89} \mathrm{Zr}-5$-trastuzumab in comparison to ${ }^{89} \mathrm{Zr}$ DFO-trastuzumab in mice revealed similar accumulation of the conjugates in the tumors but higher uptake of ${ }^{89} \mathrm{Zr}$-5-trastuzumab in the liver and bones.

Evaluation of novel chelators for ${ }^{89} \mathrm{Zr}$ currently focuses on a comparison of their individual characteristics to that of the standard chelator DFO. What is required in a next step is a comparison among the newly developed octadentate BFCAs to translate one of them into the clinic.

Although research with ${ }^{89} \mathrm{Zr}$ is centered around ${ }^{89} \mathrm{Zr}$-immunoPET, other applications such as ${ }^{89} \mathrm{Zr}$-labeled peptides (e.g., RGD, exendin4) $(30,31)$, proteins (e.g., albumin, transferrin) $(32,33)$, and nanoparticles have been reported $(34,35)$. Lately, there is also interest in the ${ }^{89} \mathrm{Zr}$ labeling of different cell types. For example, ${ }^{89} \mathrm{Zr}$ oxine or ${ }^{89} \mathrm{Zr}$-DFO- $p$-Bn-NCS have been reported for the ex vivo radiolabeling of cells $(36,37)$.

\section{${ }^{64} \mathrm{CU}$ : UNIQUE FEATURES AND CHALLENGES}

${ }^{64} \mathrm{Cu}$ decays by emission of both $\beta^{+}(17.9 \%)$, for PET imaging, and $\beta^{-}(39.0 \%)$, for radioendotherapy; ${ }^{64} \mathrm{Cu}$ can therefore be classified as a theranostic radionuclide. This fact together with the low $\beta^{+}$energy and the relatively long physical half-life $(12.7 \mathrm{~h})$ suitable for immuno-PET has kept the radiopharmaceutical and nuclear medicinal communities interested in the radiometal. Different applications of ${ }^{64} \mathrm{Cu}$ have been reported in the literature, ranging from the use of its salt ${ }^{64} \mathrm{CuCl}_{2}$ to the radiolabeling of small molecules and peptides to antibodies and nanoparticles via chelating systems (38). Although none of the reported ${ }^{64} \mathrm{Cu}$-labeled compounds has yet made it into clinical routine, intensive research is still ongoing.

Unlike other radiometals applied in radiopharmaceutical development (e.g., lanthanides and actinides as well as ${ }^{68} \mathrm{Ga}^{3+}$ or $\left.{ }^{90} \mathrm{Y}^{3+}\right)$, copper(II) is not redox-inert under physiologic conditions. When exposed to reducing conditions (e.g., hypoxic environment of tumors), $\mathrm{Cu}(\mathrm{II})$ is reduced to $\mathrm{Cu}(\mathrm{I})$, which exhibits different coordination properties $(38,39)$. The change in the oxidation number of the metal is thus presumed to be the reason for the observed instability of ${ }^{64} \mathrm{Cu}$ (II) complexes in vivo with chelators such as DOTA (Fig. 3) and TETA (Fig. 5), which results in transchelation and unspecific uptake of the radiometal in, for example, the liver. In an effort to develop chelators better suited for the stable complexation of ${ }^{64} \mathrm{Cu}$, new designs such as the sarcophagine diamSAR $\mathbf{1 1}$ or cross-bridged macrocycle systems such as CB-TE2A 10 (Fig.5) have been studied. For example, somatostatin receptor targeting with ${ }^{64} \mathrm{Cu}-\mathrm{Cu}-\mathrm{CB}-\mathrm{TE} 2 \mathrm{~A}-\mathrm{Y} 3-\mathrm{TATE}$ gave better results than the above-discussed DOTA analog Also, studies with ${ }^{64} \mathrm{Cu}-$ labeled RGDyK derivatives radiolabeled via diamSar 11 or CBTE2A 10 in mice bearing melanoma xenografts demonstrated the superiority of these chelators over DOTA and TETA in terms of tumor targeting as well as blood and liver clearance (38).

A different class of copper-based radiopharmaceuticals are complexes of ${ }^{64} \mathrm{Cu}$ formed with thiosemicarbazones (ATSM) 12 (Fig. 5), for which the redox behavior of the radiometal is in fact essential for their mode of action. ${ }^{64} \mathrm{Cu}-\mathrm{Cu}$-ATSM is under investigation for the imaging of hypoxia; only in hypoxic cells occurs the reduction of $\mathrm{Cu}$ (II) to $\mathrm{Cu}(\mathrm{I})$, which leads to the release and intracellular trapping of the copper ion. Hypoxia is associated with chemotherapy resistance, tumor aggressiveness, and cell migration and is thus an important indicator for the response of tumors to radiation therapy (40). Although the role of ${ }^{64} \mathrm{Cu}-\mathrm{ATSM}$

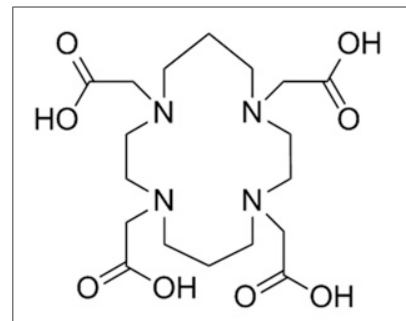

TETA 9

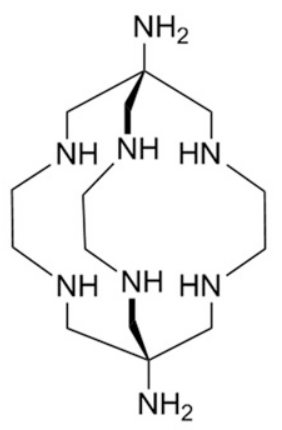

diamSar 11<smiles>O=C(O)CN1CCCN(CCCN2CCCN(CC(=O)O)CC2)CC1</smiles>

CB-TE2A 10

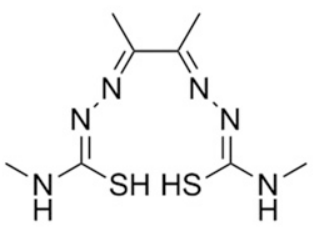

FIGURE 5. Examples of chelators reported for complexation of ${ }^{64} \mathrm{Cu}$.

for hypoxia imaging remains controversial, different clinical studies with ${ }^{64} \mathrm{Cu}$-ATSM have been conducted (41) or are currently ongoing (trial ID NCT00794339).

Although several publications highlight the unique decay characteristics of ${ }^{64} \mathrm{Cu}\left(\beta^{+}, \beta^{-}\right)$for theranostic approaches, to the best of our knowledge no reports on therapeutic applications of ${ }^{64} \mathrm{Cu}-$ labeled molecules are yet available. The only exception are preliminary investigations with ${ }^{64} \mathrm{CuCl}_{2}$ in a therapy study with 2 cervical cancer patients (42).

\section{OTHER PET RADIOMETALS AND THEIR APPLICATIONS}

Besides ${ }^{68} \mathrm{Ga},{ }^{89} \mathrm{Zr}$, and ${ }^{64} \mathrm{Cu}$, there are several other PET radiometals that need to be mentioned. ${ }^{82} \mathrm{Rb}$ is a generator-based radiometal that is used in the clinic in the form of ${ }^{82} \mathrm{RbCl}$ as a mimic of potassium ions $\left(\mathrm{K}^{+}\right)$for the imaging of myocardiac perfusion (43). The short physical half-life of ${ }^{82} \mathrm{Rb}$ (1.3 min) imposes some challenges for routine applications, but its use is justified because of the higher resolution of PET than of the most commonly used SPECT tracers (e.g., ${ }^{99 \mathrm{~m}}$ Tc-MIBI (43)).

${ }^{86} \mathrm{Y}\left(\beta^{+}\right)$forms an isotopic theranostic pair with the pure $\beta^{-}$-emitter ${ }^{90} \mathrm{Y}$. The development of the theranostic principle exemplified by the yttrium pair ${ }^{86} \mathrm{Y} /{ }^{90} \mathrm{Y}$ is the subject of a recent review (44).

${ }^{44} \mathrm{Sc}$ is another PET radiometal of recent interest. ${ }^{44} \mathrm{Sc}$ can be obtained either from a ${ }^{44} \mathrm{Ti} /{ }^{44} \mathrm{Sc}$ generator $(45)$ or by the cyclotron-production route (46) (Table 1). ${ }^{44} \mathrm{Sc}$ possesses similar decay characteristics to ${ }^{68} \mathrm{Ga}$ but a longer physical half-life $(3.97 \mathrm{~h})$, making it an interesting option for the centralized production of PET radiotracers. Proof-of-principle studies showed that ${ }^{44} \mathrm{Sc}-$ DOTATOC is compatible with standard radiolabeling techniques and results in an imaging quality comparable to that of the established ${ }^{68} \mathrm{Ga}$-DOTATOC. 
When other imaging modalities are intended to be combined with PET in a multimodal imaging approach, less established radiometals are also brought to the scene. For example, paramagnetic manganese $\left({ }^{\text {nat }} \mathrm{Mn}^{2+}\right.$ ) has been considered a potential alternative to currently used MRI contrast agents based on gadolinium $\left({ }^{\text {nat }} \mathrm{Gd}^{3+}\right)$. In this context, mixtures of nat $\mathrm{Mn}$ and the PET radiometal ${ }^{52 \mathrm{~g}} \mathrm{Mn}$ have been investigated for dual PET/MRI applications. In particular, the chelating system CDTA (trans-1,2cyclohexanediaminetetraacetic acid) was found to provide a good compromise between the stability and relaxivity of manganese complexes for applications in vivo (47).

Other examples of PET radiometals recently reported include ${ }^{152} \mathrm{~Tb}(48)$ and ${ }^{43} \mathrm{Sc}(49)$, of which the latter is of particular interest because it has a similar half-life to the isotopic ${ }^{44} \mathrm{Sc}$ but with less intense $\gamma$-lines and lower $\beta^{+}$- and $\gamma$-energies.

\section{CONCLUSION}

All PET radiometals discussed in this review have their advantages and disadvantages. Because the ideal radionuclide does not exist, often a compromise between what is desired and what is applicable or accessible needs to be found. Consequently, several aspects have to be addressed before a PET radiometal is selected for an intended application. For example, is the radiometal commercially available, or can it be produced in-house (e.g., by a generator or an existing cyclotron)? Does the physical halflife of the radiometal match the biologic half-life of the (bio) molecule for the intended purpose? Are chelators (or, better, BFCAs) for the stable complexation of the radiometal known or commercially available? If a theranostic approach is planned, are there matching therapeutic analogs of the radiometal? Lastly, what regulatory aspects need to be considered for the clinical use of the radiometal selected (e.g., good manufacturing practices)?

In a relatively short time, ${ }^{68} \mathrm{Ga}$ has become a standard PET radiometal in the clinic with good-manufacturing-practice-grade ${ }^{68} \mathrm{Ge} /{ }^{68} \mathrm{Ga}$-generators available. Other emerging, yet still nonstandard, radiometals (e.g., ${ }^{64} \mathrm{Cu},{ }^{89} \mathrm{Zr}$ ) have high potential to find established applications in nuclear medicine. Taking together the advantages that various (PET) radiometals offer (e.g., in combination with theranostic approaches), it is anticipated that this research field will continue to gain momentum in both radiopharmacy and nuclear medicine in the future.

\section{REFERENCES}

1. van de Watering FC, Rijpkema M, Perk L, Brinkmann U, Oyen WJ, Boerman OC. Zirconium-89 labeled antibodies: a new tool for molecular imaging in cancer patients. BioMed Res Int. 2014;2014:203601.

2. Velikyan I. Prospective of ${ }^{68} \mathrm{Ga}$-radiopharmaceutical development. Theragnostics. 2014;4:47-80.

3. Ballinger JR. Short- and long-term responses to molybdenum-99 shortages in nuclear medicine. Br J Radiol. 2010;83:899-901.

4. Kelkar SS, Reineke TM. Theranostics: combining imaging and therapy. Bioconjug Chem. 2011;22:1879-1903.

5. Beauregard J-M, Hofman MS, Pereira JM, Eu P, Hicks RJ. Quantitative ${ }^{177} \mathrm{Lu}$ SPECT (QSPECT) imaging using a commercially available SPECT/CT system. Cancer Imaging. 2011;11:56-66.

6. Jalilian AR, Osso J Jr. The current status and future of theranostic copper-64 radiopharmaceuticals. Iran J Nucl Med. 2017;25:1-10.

7. Poschenrieder A, Schottelius M, Schwaiger M, Kessler H, Wester HJ. The influence of different metal-chelate conjugates of pentixafor on the CXCR4 affinity. EJNMMI Res. 2016;6:36.

8. Herzog H, Rösch F, Stöcklin G, Lueders C, Qaim SM, Feinendegen LE. Measurement of pharmacokinetics of yttrium-86 radiopharmaceuticals with PET and radiation dose calculation of analogous yttrium-90 radiotherapeutics. $J$ Nucl Med. 1993;34:2222-2226.

9. Notni J, Wester HJ. Re-thinking the role of radiometal isotopes: towards a future concept for theranostic radiopharmaceuticals. J Labelled Comp Radiopharm. 2018;61:141-153.

10. Rösch F. Past, present and future of ${ }^{68} \mathrm{Ge} /{ }^{68} \mathrm{Ga}$ generators. Appl Radiat Isot. 2013;76:24-30.

11. Anger HO, Gottschalk A. Localization of brain tumors with the positron scintillation camera. J Nucl Med. 1963;4:326-330.

12. Hofmann M, Maecke H, Börner A, et al. Biokinetics and imaging with the somatostatin receptor PET radioligand ${ }^{68} \mathrm{Ga}$-DOTATOC: preliminary data. Eur J Nucl Med. 2001;28:1751-1757.

13. Haug A, Auernhammer CJ, Wangler B, et al. Intraindividual comparison of ${ }^{68} \mathrm{Ga}$-DOTA-TATE and ${ }^{18} \mathrm{~F}$-DOPA PET in patients with well-differentiated metastatic neuroendocrine tumours. Eur J Nucl Med Mol Imaging. 2009;36: $765-770$.

14. Smith DL, Breeman WA, Sims-Mourtada J. The untapped potential of gallium 68-PET: the next wave of ${ }^{68} \mathrm{Ga}$-agents. Appl Radiat Isot. 2013;76:14-23.

15. Alves F, Alves VH, Neves ACB, et al. Cyclotron production of Ga-68 for human use from liquid targets: from theory to practice. AIP Conf Proc. 2017;1845: 10.1063/1.4983532.

16. Tsionou MI, Knapp CE, Foley CA, et al. Comparison of macrocyclic and acyclic chelators for gallium-68 radiolabelling. RSC Advances. 2017;7:4958649599.

17. Sanchez-Crespo A. Comparison of gallium-68 and fluorine-18 imaging characteristics in positron emission tomography. Appl Radiat Isot. 2013;76:55-62.

18. Meijs WE, Herscheid JD, Haisma HJ, Pinedo HM. Evaluation of desferal as a bifunctional chelating agent for labeling antibodies with Zr-89. Int J Rad Appl Instrum [A]. 1992;43:1443-1447.

19. Börjesson PK, Jauw YW, Boellaard R, et al. Performance of immuno-positron emission tomography with zirconium-89-labeled chimeric monoclonal antibody U36 in the detection of lymph node metastases in head and neck cancer patients. Clin Cancer Res. 2006;12:2133-2140.

20. Heskamp S, Raavé R, Boerman O, Rijpkema M, Goncalves V, Denat F. ${ }^{89} \mathrm{Zr}$ immuno-positron emission tomography in oncology: state-of-the-art ${ }^{89} \mathrm{Zr}$ radiochemistry. Bioconjug Chem.2017;28:2211-2223.

21. Severin GW, Engle JW, Barnhart TE, Nickles RJ. ${ }^{89} \mathrm{Zr}$ radiochemistry for positron emission tomography. Med Chem. 2011;7:389-394.

22. Abou DS, Ku T, Smith-Jones PM. In vivo biodistribution and accumulation of ${ }^{89} \mathrm{Zr}$ in mice. Nucl Med Biol. 2011;38:675-681.

23. Patra M, Bauman A, Mari C, et al. An octadentate bifunctional chelating agent for the development of stable zirconium- 89 based molecular imaging probes. Chem Commun (Camb). 2014;50:11523-11525.

24. Vugts DJ, Klaver C, Sewing C, et al. Comparison of the octadentate bifunctional chelator DFO*-pPhe-NCS and the clinically used hexadentate bifunctional chelator DFO-pPhe-NCS for ${ }^{89} \mathrm{Zr}$-immuno-PET. Eur J Nucl Med Mol Imaging. 2017; 44:286-295.

25. Briand M, Aulsebrook ML, Mindt TL, Gasser G. A solid phase-assisted approach for the facile synthesis of a highly water-soluble zirconium- 89 chelator for radiopharmaceutical development. Dalton Trans. 2017;46:16387-16389.

26. Rudd SE, Roselt P, Cullinane C, Hicks RJ, Donnelly PS. A desferrioxamine B squaramide ester for the incorporation of zirconium-89 into antibodies. Chem Commun (Camb). 2016;52:11889-11892.

27. Deri MA, Ponnala S, Zeglis BM, et al. Alternative chelator for ${ }^{89} \mathrm{Zr}$ radiopharmaceuticals: radiolabeling and evaluation of 3,4,3-(LI-1,2-HOPO). J Med Chem. 2014;57:4849-4860.

28. Deri MA, Ponnala S, Kozlowski P, et al. p-SCN-Bn-HOPO: a superior bifunctional chelator for ${ }^{89} \mathrm{Zr}$ immunoPET. Bioconjug Chem. 2015;26:2579-2591.

29. Tinianow JN, Pandya DN, Pailloux SL, et al. Evaluation of a 3-hydroxypyridin2-one (2,3-HOPO) based macrocyclic chelator for $89 \mathrm{Zr} 4+$ and its use for immunopet imaging of HER2 positive model of ovarian carcinoma in mice. Theranostics. 2016;6:511-521.

30. Jacobson O, Zhu L, Niu G, et al. MicroPET imaging of integrin $\alpha v \beta 3$ expressing tumors using ${ }^{89} \mathrm{Zr}$-RGD peptides. Mol Imaging Biol. 2011;13:1224-1233.

31. Bauman A, Valverde IE, Fischer CA, Vomstein S, Mindt TL. Development of ${ }^{68} \mathrm{Ga}$-and ${ }^{89} \mathrm{Zr}$-labeled exendin-4 as potential radiotracers for the imaging of insulinomas by PET. J Nucl Med. 2015;56:1569-1574.

32. Heneweer C, Holland JP, Divilov V, Carlin S, Lewis JS. Magnitude of enhanced permeability and retention effect in tumors with different phenotypes: ${ }^{89} \mathrm{Zr}$ albumin as a model system. J Nucl Med. 2011;52:625-633.

33. Evans MJ, Holland JP, Rice SL, et al. Imaging tumor burden in the brain with ${ }^{89} \mathrm{Zr}$-transferrin. J Nucl Med. 2013;54:90-95.

34. Keliher EJ, Yoo J, Nahrendorf M, et al. ${ }^{89} \mathrm{Zr}$-labeled dextran nanoparticles allow in vivo macrophage imaging. Bioconjug Chem. 2011;22:2383-2389. 
35. Pérez-Medina C, Tang J, Abdel-Atti D, et al. PET imaging of tumor-associated macrophages with ${ }^{89} \mathrm{Zr}$-labeled high-density lipoprotein nanoparticles. $\mathrm{J} \mathrm{Nucl}$ Med. 2015;56:1272-1277.

36. Bansal A, Pandey MK, Demirhan YE, et al. Novel ${ }^{89} \mathrm{Zr}$ cell labeling approach for PET-based cell trafficking studies. EJNMMI Res. 2015;5:19.

37. Sato N, Wu H, Asiedu KO, Szajek LP, Griffiths GL, Choyke PL. ${ }^{89} \mathrm{Zr}$-oxine complex PET cell imaging in monitoring cell-based therapies. Radiology. 2015;275:490-500.

38. Anderson CJ, Ferdani R. Copper-64 radiopharmaceuticals for PET imaging of cancer: advances in preclinical and clinical research. Cancer Biother Radiopharm. 2009;24:379-393.

39. Conry RR. Copper: inorganic \& coordination chemistry. In: Encyclopedia of Inorganic Chemistry. Hoboken NJ: John Wiley \& Sons, Ltd; 2006.

40. Fujibayashi Y, Taniuchi H, Yonekura Y, Ohtani H, Konishi J, Yokoyama A. Copper-62-ATSM: a new hypoxia imaging agent with high membrane permeability and low redox potential. J Nucl Med. 1997;38:1155-1160.

41. Dehdashti F, Grigsby PW, Mintun MA, Lewis JS, Siegel BA, Welch MJ. Assessing tumor hypoxia in cervical cancer by positron emission tomography with ${ }^{60} \mathrm{Cu}$-ATSM: relationship to therapeutic response-a preliminary report. Int $J$ Radiat Oncol Biol Phys. 2003;55:1233-1238.

42. Valentini G, Panichelli P, Villano C, Pigotti G, Martini D. ${ }^{64} \mathrm{CuCl}_{2}$ : new theranostic agent [abstract]. Nucl Med Biol. 2014;41:638.
43. Chatal J-F, Rouzet F, Haddad F, Bourdeau C, Mathieu C, Le Guludec D. Story of rubidium-82 and advantages for myocardial perfusion PET imaging. Front Med (Lausanne). 2015;2:65.

44. Rösch F, Herzog H, Qaim S. The beginning and development of the theranostic approach in nuclear medicine, as exemplified by the radionuclide pair $86 \mathrm{Y}$ and ${ }^{90}$ Y. Pharmaceuticals (Basel). 2017;10:56.

45. Pruszyński M, Loktionova NS, Filosofov DV, Rosch F. Post-elution processing of ${ }^{44} \mathrm{Ti} /{ }^{44} \mathrm{Sc}$ generator-derived ${ }^{44} \mathrm{Sc}$ for clinical application. Appl Radiat Isot. 2010; 68:1636-1641.

46. Alliot C, Kerdjoudj R, Michel N, Haddad F, Huclier-Markai S. Cyclotron production of high purity ${ }^{44 \mathrm{~m}, 44} \mathrm{Sc}$ with deuterons from ${ }^{44} \mathrm{CaCO} 3$ targets. Nucl Med Biol. 2015;42:524-529.

47. Vanasschen C, Brandt M, Ermert J, Coenen HH. Radiolabelling with isotopic mixtures of ${ }^{52 \mathrm{~g} / 55} \mathrm{Mn}$ (II) as a straight route to stable manganese complexes for bimodal PET/MR imaging. Dalton Trans. 2016;45:13151321.

48. Müller C, Vermeulen C, Johnston K, et al. Preclinical in vivo application of ${ }^{152} \mathrm{~Tb}$-DOTANOC: a radiolanthanide for PET imaging. EJNMMI Res. 2016; $6: 35$.

49. Walczak R, Krajewski S, Szkliniarz K, et al. Cyclotron production of ${ }^{43} \mathrm{Sc}$ for PET imaging. EJNMMI Phys. 2015;2:33. 